\title{
In vitro Digestibility of Starch from Ready-to-Eat Cassava and Corn Flours
}

\section{Camila Sztoltz Piroski ${ }^{1}$}

https://orcid.org/0000-0002-4913-7468

Ana Cláudia Bedin 1

https://orcid.org/0000-0002-6844-1983

\section{Luiz Gustavo Lacerda ${ }^{1}$}

https://orcid.org/0000-0002-4689-5431

\section{Alessandro Nogueira ${ }^{1}$}

https://orcid.org/0000-0001-7671-3056

\section{Ivo Mottin Demiate ${ }^{1 *}$}

https://orcid.org/0000-0002-5609-0186

1State University of Ponta Grossa, Graduate Program in Food Science and Technology, Ponta Grossa, Paraná, Brazil.

Editor-in-Chief: Paulo Vitor Farago

Associate Editor: Paulo Vitor Farago

Received: 2020.11.04; Accepted: 2021.03.04.

*Correspondence: demiate@uepg.br; Tel.: +55-42-32203268 (I.M.D.).

\section{HIGHLIGHTS}

- Ready-to-eat flours, used without further processing, deliver raw starch to diet.

- Dry cassava flour had the best starch digestibility profile from all samples.

- Processing of the flours influences starch gelatinization degree and digestibility.

- Consumption of cassava flour can benefit nutritional quality of a meal.

Abstract: Slowly digestible starch (SDS) and resistant starch (RS) associate with health benefits when present in the diet. This study aimed to evaluate ready-to-eat corn and cassava flours regarding their commercial presentation (dry or flaked), composition and in vitro digestibility of starch. Sixteen samples from Southern Brazil were procured in the market: eight dry cassava flours, six biju-type (flaked) corn flours and two biju-type cassava flours. Dry cassava flours had higher $L^{*}$ and lower $b^{*}$ values, and higher RS, relative crystallinity and viscosity peak values. Dry cassava flour partially preserves granular starch, as its processing involves lower drying temperatures and lower moisture of the pressed pulp. Dry cassava flours that had higher $b^{*}$ values also had higher rapidly digestible starch (RDS) levels, since higher temperatures are required in their production. Both biju-type flours showed the highest RDS values and no RS due to processing with elevated temperature and high moisture of the pressed pulp. In this study starch digestibility from the flours depended on processing, with minor influence of the raw material, fiber content 
and granulometry. The whiter and the smaller the granulometry of the dry cassava flours, the better they showed as potentially health benefiting.

Keywords: Englyst method; amylase from porcine gastric mucosa; resistant starch.

\section{INTRODUCTION}

Brazilians have peculiar everyday-meals that include rice and beans as the main energy sources. Other low-cost foods are also present, including ready-to-eat (pre-cooked) flours from cassava or from corn. The main animal protein sources are chicken, beef, pork, eggs and fish, sometimes consumed in limited amounts by the lower income population.

In the present study, cassava and corn ready-to-eat flours were procured from the local market and analyzed by selected physicochemical and instrumental methods to find out their potential health benefits when consumed without additional cooking. Consuming those flours together with the daily meals is very frequent throughout Brazil, both during the week as well as with special weekend-dishes (roasted beef, barbecue). Differently from other countries that prefer barbecue with special sauces (ketchup, barbecue sauce, mustard sauce, and others), in general, Brazilians prefer cassava or corn flours, which frequently help to reduce the fatty aspect of the dish.

The processing of corn and cassava flours includes several steps that contribute to changes in important physicochemical and sensory properties. The Brazilian corn flour differs from those of most countries because it is a pre-cooked, flaked, ready-to-eat food. Its production involves wet milling corn kernels, differing from the conventional dry milling that is standard for corn flour worldwide. In Brazil the corn flour from dry milling is known as "Fubá" [1]. The wet milling of corn flour includes steeping of whole corn kernel or of the corn endosperm in drinking water for one to two days followed by grinding and sieving over a rotary hot plate oven. As starch gelatinizes, flakes are produced and the "Biju"-type corn flour [2] is ready to be packed in one-kilogram (less frequently in half-kilogram) plastic bags. In the case of "Biju"-type cassava flour, the process of drying and flaking the product is similar. The main difference is that cassava roots have high moisture and after being grinded, the obtained pulp is pressed to eliminate the excess water and then it is dried on the rotary hot plate oven (flaked). The aim of the present study was to investigate potential health benefits of Brazilian precooked cassava and corn flours especially related to their starch digestibility.

\section{MATERIAL AND METHODS}

Six samples of corn flour (BCO1-BCO6, half of them from yellow and half from white corn) and ten samples of cassava flour (CA1-CA8 and BCA1-BCA2) were procured in retail markets from two cities of South Brazil (Ponta Grossa, PR and Itaiópolis, SC). Guar gum (Sigma-Aldrich, St. Louis, EUA), Porcine pancreatic a-amylase (E.C. 3.2.1.1, Sigma-Aldrich, $8 \times$ USP specifications, P7545), amyloglucosidase from Aspergillus niger (E.C. 3.2.1.3, Sigma-Aldrich, $\geq 260 \mathrm{U} / \mathrm{mL}$, A7095) were used for the in vitro starch digestibility analyses. For quantification of total starch contents, Total Starch Assay Kit (AA/AMG, K-TSTA) and D-Glucose Assay Kit (GOPOD format, K-GLUC) were purchased from Megazyme International (Wicklow, Ireland). All other chemicals were reagent grade and were used without further purification.

\section{Proximal composition}

The contents of moisture 934.01 method [3], protein 920.87 method, 6.25 factor [3], lipids (Soxhlet/hexane) [4], ash 942.05 method [3], dietary fiber 985.29 [5], total starch 996.11 method [3] and total carbohydrate (by difference) were determined for the flours.

\section{Instrumental color}

Color was evaluated by using a handheld MiniScan EZ 4500L spectrophotometer (Hunter Lab, USA) with CIE L*, $a^{*}$ and $b^{*}$ system [6]. The Whiteness Index (WI) was calculated by the Equation 1 [7].

$$
W I=\left[\left(100-L^{\star} 2\right)+a^{\star} 2+b^{\star} 2\right] 0.5
$$




\section{Granulometry}

Approximately $100 \mathrm{~g}$ of sample was passed through a sequence of sieves $(1.19 \mathrm{~mm} ; 0.841 \mathrm{~mm} ; 0.595$ $\mathrm{mm} ; 0.420 \mathrm{~mm} ; 0.250 \mathrm{~mm} ; 0.105 \mathrm{~mm}$ and $<0.105 \mathrm{~mm}$ ) mounted on a mechanical vibrator (Bertel Indústria Metalúrgica Ltda., Caieiras SP, Brazil). All separated fractions were weighed.

\section{Pasting properties}

Pasting properties were evaluated using a Rapid Visco Analyser (RVA-4, Newport Scientific, Australia). The flours were weighed to produce an $8 \%(\mathrm{w} / \mathrm{w}$, dry basis) suspension in distilled water, totaling $28 \mathrm{~g}$ in the RVA aluminium canister. The suspension was stabilized at $50{ }^{\circ} \mathrm{C}$ for one minute and then heated from 50 to $95{ }^{\circ} \mathrm{C}$ at $6{ }^{\circ} \mathrm{C} / \mathrm{min}$ rate, kept under stirring cooking at $95{ }^{\circ} \mathrm{C}$ for $6 \mathrm{~min}$, and then cooled to $50{ }^{\circ} \mathrm{C}$ at 6 ${ }^{\circ} \mathrm{C} / \mathrm{min}$ rate. After one minute at $50{ }^{\circ} \mathrm{C}$, the analysis was concluded [8].

\section{Water and oil holding capacity (WHC / OHC)}

Water and oil holding capacity followed the method described elsewhere [9], with little modifications. Two grams of sample was mixed with $30 \mathrm{~mL}$ of water or vegetable oil in centrifuge tubes. Those suspensions were mixed by $30 \mathrm{~min}$ and then centrifuged at 2,000 $\times \mathrm{g}$. The precipitate was weighed for calculating $\mathrm{WHC}$ and $\mathrm{OHC}$.

\section{Differential Scanning Calorimetry (DSC)}

The gelatinization temperature and enthalpy change of gelatinization were analyzed by using a TA Q200 DSC equipment (TA Instruments, New Castle DE, USA). Two milligrams (dry basis) of sample was mixed with $8 \mu \mathrm{L}$ of distilled water inside aluminium DSC pans. After one hour resting at room temperature to equilibrate, the samples were exposed to heating $\left(10^{\circ} \mathrm{C} / \mathrm{min}\right)$ from $30-100{ }^{\circ} \mathrm{C}$, with air flow at 50 $\mathrm{mL} / \mathrm{min}$. The equipment was calibrated with Indium (melting point $=156.6{ }^{\circ} \mathrm{C} ; \Delta \mathrm{H}=28.56 \mathrm{~J} / \mathrm{g}$ ). Endotherms were generated with the corresponding gelatinization temperatures $\left(T_{0}, T_{p}, T_{c}\right)$ and the enthalpy changes $(\Delta \mathrm{H}, \mathrm{J} / \mathrm{g})$ were calculated [10].

\section{X-ray powder diffraction}

The crystallinity character of the starchy flours was studied by using the X-ray powder diffraction technique. The diffractograms were collected in a Rigaku Ultima IV equipment (Tokyo, Japan) with CuKa radiation $(\lambda=1.544 \AA)$ at $40 \mathrm{kV}$ and $30 \mathrm{~mA}(10)$. The analysis was performed at $20^{\circ} \mathrm{C}$ between $3-40^{\circ}(2 \theta$ angle) with continuous scanning. The relative crystallinity $(\mathrm{RC})$ was calculated considering the relation between peak area and total area [11].

\section{Scanning Electron Microscopy (SEM)}

The scanning electron microscopy was carried out with a Tescan - VEGA 3 (Brno-Kohoutovice, Czech Republic), with $15 \mathrm{kV}$ voltage tension and selected magnification values $(160 \times ; 1,000 \times ; 3,500 \times$ and $5,000 \times)$. The samples were metalized with gold as described for starch samples [12].

\section{In vitro starch digestibility}

Starch digestibility of the flours was analyzed by the Englyst method [13]. The digestion of the corn and cassava flours was based in the method described for starch in vitro digestibility. In $50 \mathrm{~mL}$ plastic tubes 900 $\mathrm{mg}$ of sample and $50 \mathrm{mg}$ of guar gum was weighed, five ball glasses ( $5 \mathrm{~mm}$ diameter) were added together with $20 \mathrm{~mL}$ of acetate buffer $(0.1 \mathrm{M} \mathrm{pH} 5.2)$. The tubes were put inside a water bath at $37^{\circ} \mathrm{C}$ for $5 \mathrm{~min}$ for temperature stabilization. After temperature equilibration, $5 \mathrm{~mL}$ of enzymatic solution (Porcine pancreatic $\alpha$ amylase and amyloglucosidase from Aspergillus niger) was added. After 20 min and 120 min of incubation at $37^{\circ} \mathrm{C}, 0.250 \mathrm{~mL}$ aliquots of the solution were collected (G20 and $\mathrm{G} 120$, respectively) and transferred to tubes containing $10 \mathrm{~mL}$ of $66 \%(\mathrm{v} / \mathrm{v})$ ethanol to stop the enzymatic digestion. The tubes were centrifuged at $1,000 \times \mathrm{g}$ for $5 \mathrm{~min}$. A fraction from the supernatant was collected and used to measure glucose (TG) by the GOPOD method. Total starch was determined as described above.

The values of G20, G120 and GT were used to calculate total starch (TS), RDS, SDS and RS as follows: 


$$
\begin{aligned}
& \mathrm{TS}=(\mathrm{TG}) \times 0.9 \\
& \mathrm{RDS}=(\mathrm{G} 20) \times 0.9 \\
& \mathrm{SDS}=(\mathrm{G} 120-\mathrm{G} 20) \times 0.9 \\
& \mathrm{RS}=\mathrm{TS}-\mathrm{SDS}-\mathrm{RDS} \text { or }(\mathrm{TG}-\mathrm{G} 120) \times 0.9
\end{aligned}
$$

Where: $\mathrm{TS}=$ Total starch; $\mathrm{TG}=$ Total glucose; RDS = Rapidly Digestible Starch; SDS = Slowly Digestible Starch; RS = Resistant Starch.

\section{Statistical Analysis}

Statistical analysis was performed by the ANOVA $(p \leq 0.05)$ followed by the Fisher LSD test. The homogeneity of variance was checked by the Brown-Forsythe test $(p>0.05)$. The linear correlations among variables were calculated and expressed as the Pearson correlation coefficients. Statistical analyses were made by using the STATISTICA software version 13.2 (Tibco, Palo Alto CA, USA).

\section{RESULTS}

The proximate composition of the flours showed the higher contents of protein and lipids and lower starch levels from corn flours when compared with cassava flours (Figure 1). This is explained by the differences between the composition of the raw materials, corn kernels and cassava roots, respectively.

There is predominance of carbohydrates in all flours, mainly starch (85.1-95.8\%, d.b.). Dietary fiber (DF) contents in the majority of the samples were roughly $5 \%$, but in two corn flours no DF was found, whilst in another $1.1 \%$; one cassava flour also presented a low value $(1.5 \%)$.

\section{Color analysis}

\begin{tabular}{|c|c|c|c|c|}
\hline Sample & $\mathrm{L}^{*}$ & $a^{*}$ & $\mathbf{b}^{*}$ & Whiteness index \\
\hline CA1 & $77.2 \pm 2.0^{\mathrm{ed}}$ & $1.3 \pm 0.0^{j}$ & $8.8 \pm 0.4^{k j}$ & $75.5 \pm 1.8^{\mathrm{e}}$ \\
\hline CA2 & $83.0 \pm 1.0^{\mathrm{cb}}$ & $1.7 \pm 0.1^{i}$ & $9.7 \pm 0.2^{\mathrm{ji}}$ & $85.0 \pm 0.4^{a}$ \\
\hline CA3 & $88.7 \pm 0.6^{a}$ & $1.0 \pm 0.0^{k}$ & $8.3 \pm 0.6^{k}$ & $81.0 \pm 1.1^{b}$ \\
\hline CA4 & $76.5 \pm 0.2^{\mathrm{e}}$ & $5.3 \pm 0.0^{c}$ & $26.4 \pm 0.1^{d}$ & $64.2 \pm 0.2^{h}$ \\
\hline CA5 & $72.9 \pm 3.0^{f}$ & $2.7 \pm 0.1^{f}$ & $15.7 \pm 0.4^{9}$ & $68.6 \pm 2.4^{9}$ \\
\hline CA6 & $79.5 \pm 0.5^{d}$ & $3.4 \pm 0.2^{e}$ & $17.8 \pm 0.2^{f}$ & $72.6 \pm 0.5^{f}$ \\
\hline CA7 & $85.1 \pm 0.4^{\mathrm{cb}}$ & $2.3 \pm 0.0^{g}$ & $15.1 \pm 0.1^{g}$ & $78.6 \pm 0.3^{d c}$ \\
\hline CA8 & $85.2 \pm 1.3^{b}$ & $1.7 \pm 0.0^{i}$ & $12.5 \pm 0.1^{\mathrm{h}}$ & $80.6 \pm 0.9^{\mathrm{cb}}$ \\
\hline BCO1 & $83.3 \pm 1.4^{\mathrm{cb}}$ & $0.7 \pm 0.1^{\prime}$ & $15.5 \pm 1.1^{g}$ & $77.2 \pm 1.1^{\mathrm{ed}}$ \\
\hline $\mathrm{BCO} 2$ & $71.9 \pm 3.1^{g f}$ & $6.5 \pm 0.2^{b}$ & $40.3 \pm 0.6^{b}$ & $50.4 \pm 1.3^{j}$ \\
\hline $\mathrm{BCO} 3$ & $69.6 \pm 3.2^{g}$ & $8.8 \pm 0.1^{a}$ & $45.1 \pm 1.1^{a}$ & $44.9 \pm 1.0^{k}$ \\
\hline $\mathrm{BCO} 4$ & $78.9 \pm 0.2^{\mathrm{ed}}$ & $5.3 \pm 0.0^{c}$ & $38.6 \pm 0.1^{c}$ & $55.7 \pm 0.1^{i}$ \\
\hline BCO5 & $85.3 \pm 0.3^{b}$ & $0.2 \pm 0.0^{m}$ & $10.5 \pm 0.4^{i}$ & $81.9 \pm 0.5^{b}$ \\
\hline BCO6 & $82.5 \pm 0.9^{c}$ & $1.2 \pm 0.0^{j}$ & $15.1 \pm 0.4^{g}$ & $76.9 \pm 0.4^{\mathrm{ed}}$ \\
\hline BCA1 & $76.9 \pm 1.3^{\mathrm{ed}}$ & $3.8 \pm 0.2^{d}$ & $19.7 \pm 1.7^{e}$ & $69.4 \pm 2.1^{\mathrm{g}}$ \\
\hline BCA2 & $73.3 \pm 1.3^{f}$ & $2.1 \pm 0.1^{\mathrm{h}}$ & $14.9 \pm 0.7^{g}$ & $69.4 \pm 1.4^{9}$ \\
\hline $\begin{array}{l}\text { p-Brown- } \\
\text { Forsythe*** }\end{array}$ & 0.69 & 0.84 & 0.89 & 0.73 \\
\hline p-Anova ${ }^{\star * *}$ & $<0.0001$ & $<0.0001$ & $<0.0001$ & $<0.0001$ \\
\hline
\end{tabular}

The color parameters $\left(L^{*}, a^{*}, b^{*}\right)$ of the flours are presented in the Table 1 , including the whiteness index.

Table 1. Color parameters of the flours and whiteness index.

For dry cassava flours (CA1-CA8), the $L^{*}$ value ranged 72.9 - 88.7 (CA5 and CA2, respectively). Drying ovens operating at lower temperatures result in lighter color cassava flours [14], whereas drying ovens with lower loads and higher temperatures will produce darker color cassava flours due to the more intense Maillard reactions that take place. The cassava flours had whiteness index ranging from 64.2 to 85.0 and these values are directly related with the toasting degree as well as with other aspects like the 
efficiency of the peeling of the roots. Dark peels (gray to brown) from cassava roots if not completely removed can be incorporated in the flour that acquires darker color.

When considering the $b^{*}$ value, which tends to yellow color, the corn flours (BCO2, BCO 3 and $\left.\mathrm{BCO} 4\right)$ had the higher values because the corn grains used as raw materials for their production were yellow/orange in color. After those yellow corn flours, the yellower sample was MA4, which is classified as toasted cassava flour due to an additional toasting step during its production.

In other Brazilian regions, especially in Northern, yellow dyes are used, and $b$ * values much higher are produced [15]. The flours from the present study were not stained and their color depended on the raw material quality and on the adopted processing (drying /toasting).

\section{Granulometry of the flours}

As expected, the flaked flours (biju-type) had larger granulometric fractions (Figure 1). In the case of cassava flours, granulometry variation was due to the adopted processing method. What most affect granulometry are the screen openings used by the factories after the drying/toasting step. The same producer can adjust the screens to segregate flours with different granulometry profiles, to be commercialized in distinct markets. The cassava flours that were lighter in color have the smaller granulometry. Lower temperatures of the ovens are associated with these whiter and finer flours with partial preservation of the granular starch that was not completely gelatinized. There is no agglomeration of raw, uncooked, granular starch accounting for the fine fraction.

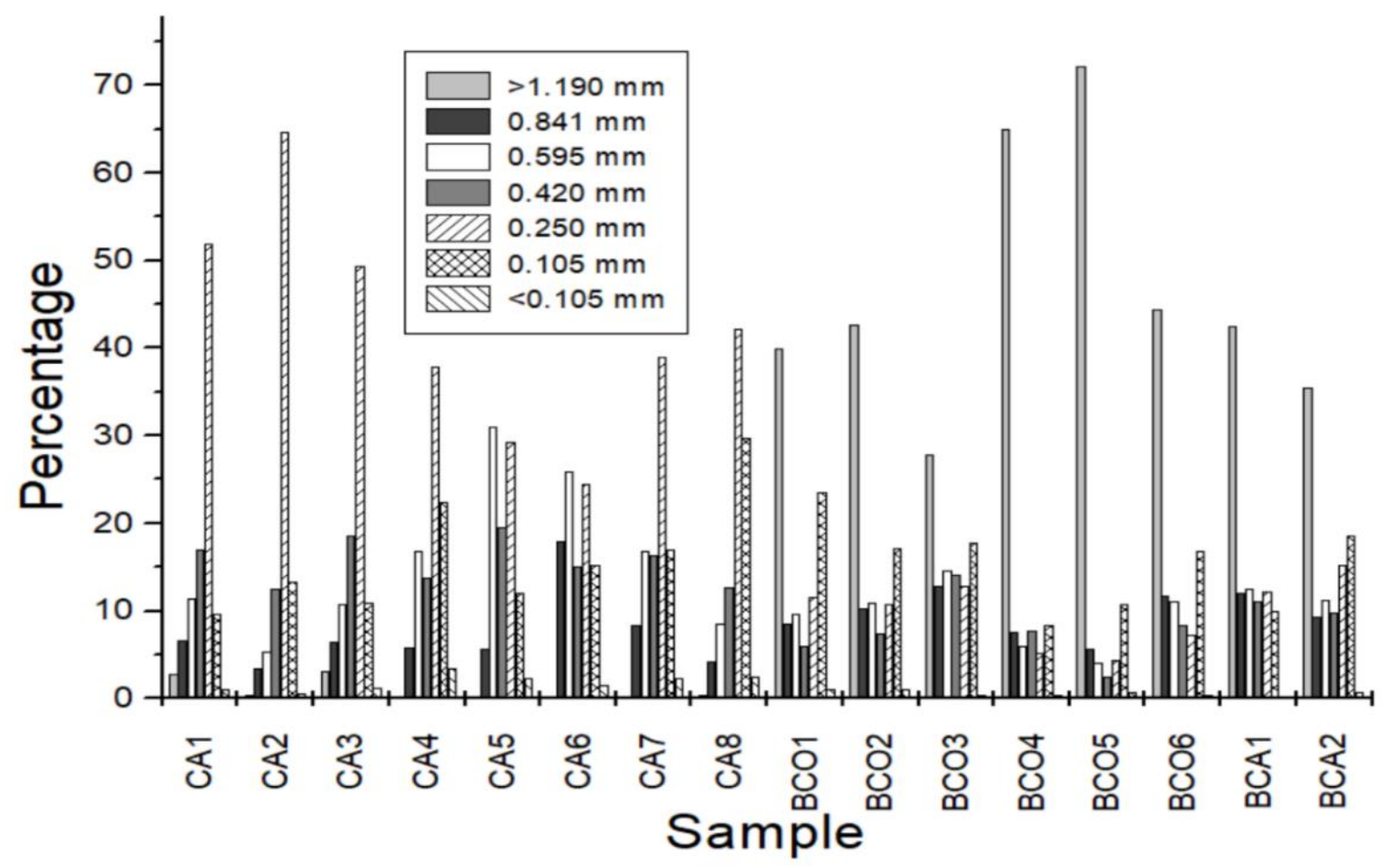

Figure 1. Granulometry distribution of the fractions.

In the case of flaked (biju-type) flours, no sifting is made after drying / toasting on the hot plate oven and the flakes will break during the removal from the oven as well as during packaging. Ideally the flakes should keep their shapes and sizes, without excessive breaking.

\section{Pasting properties}

The RVA analysis shows the cooking profile of the flours in excess water ( $8 \%$, w/w, d.b.). The starch granules absorb water and swell resulting in a viscous polymeric solution. During cooling, polymers rearrange and the viscosity increases. The pasting profiles of the flours are showed in the Figure 2. 


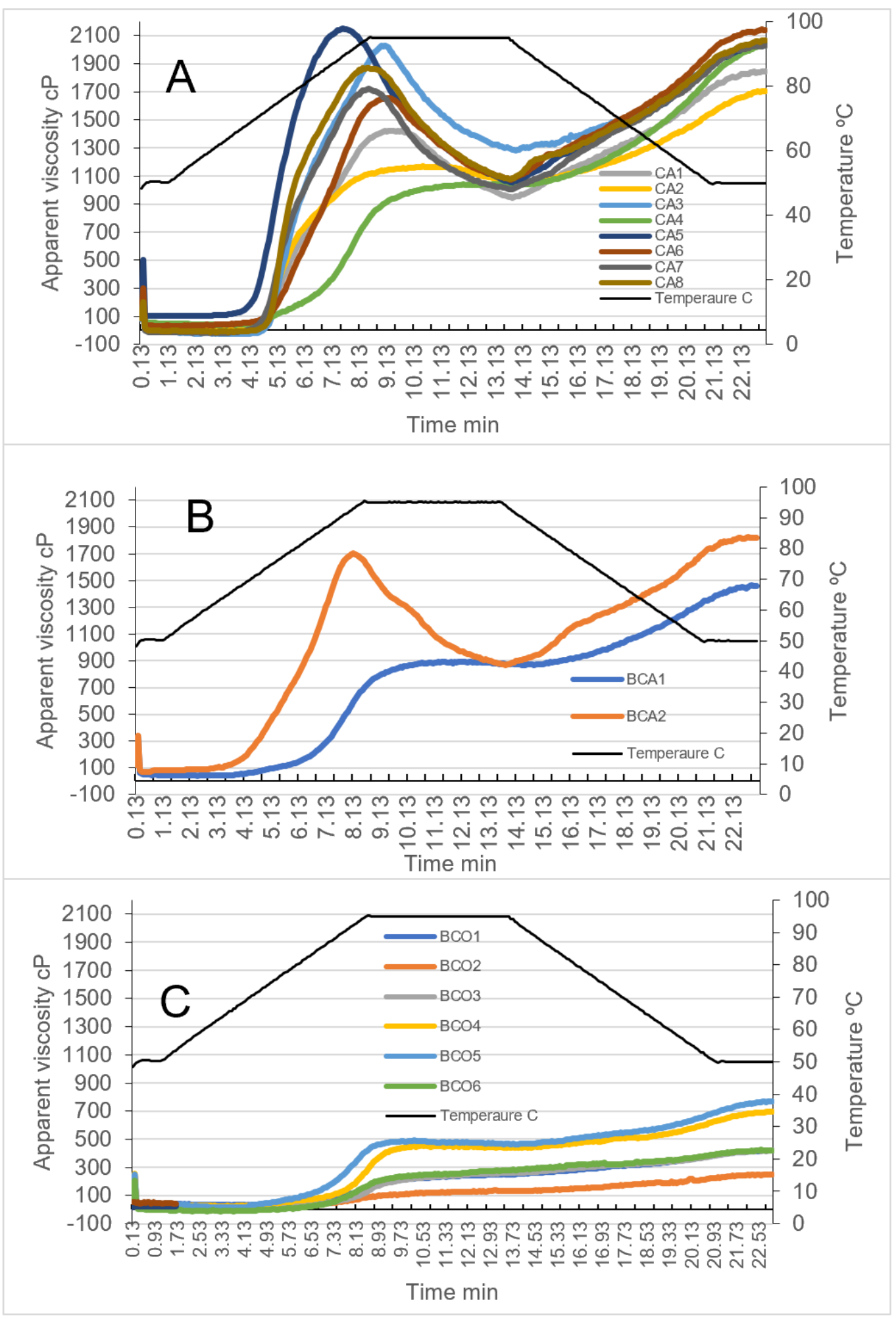

Figure 2. Pasting properties of the flours: $(A)$ dry cassava (CA1 - CA8), (B) flaked cassava (BCA1 and $\mathrm{BCA} 2)$ and (C) flaked corn (BCO1 - BCO6).

Cooking profiles of the flaked corn flours were flat if compared with the other samples. In those flours starch is expected to be almost completely gelatinized and that is why the viscosity peak is not as high as in the other samples. Marked differences in the pasting properties of the starches from corn and cassava are visible (Figure $2 \mathrm{~A}-\mathrm{C}$ ).

The dry cassava flours (CA1 -CA8) had higher viscosity peaks indicating the presence of starch granules that will swell during cooking, increasing considerably the viscosity (Figure 2A). The sample CA4, which was the darker color (lower whiteness index) cassava flour, had the lower viscosity peak, meaning that it was toasted and had the highest degree of starch gelatinization. 


\section{Water and Oil holding capacity (WHC / OHC)}

Starch granules that were completely gelatinized suffer uncoil of double helices absorbing larger amounts both of water and oil. There was a clear tendency showing that samples cooked/toasted in a more severe way (biju-type samples) presented the highest WHC and $\mathrm{OHC}$ values, in the ranges $398-540 \%$ and $239-361 \%$, respectively. In the case of the dry cassava flours, those values ranged $303-504 \%$ and $155-235 \%$, respectively.

Despite the flaked flours (biju-type) had larger granulometry profiles than the finer flours, they absorbed superior amounts of water and oil. Therefore, in this study, starch gelatinization degree [16] and the different levels of dietary fiber were more important than the surface/volume ratio of the flour particles for $\mathrm{WHC}$ and $\mathrm{OHC}$.

\section{Differential Scanning Calorimetry (DSC)}

The gelatinization temperatures $\left(T_{0}, T_{p}, T_{c},{ }^{\circ} \mathrm{C}\right)$ and the enthalpy change of gelatinization $(\Delta H)$ of starches present in the flours are showed in the Table 2. The DSC curves are also showed to help understanding the differences among samples (Figure 3).

Table 2. DSC parameters for the cassava and corn flours.

\begin{tabular}{|c|c|c|c|c|}
\hline Samples & T0 (C) & Tp (으) & Tc (ㄷ) & $\Delta \mathrm{H}(\mathrm{J} / \mathrm{g})$ \\
\hline CA1 & $64.7 \pm 0.1^{h}$ & $71.2 \pm 0.3^{\text {fed }}$ & $76.8 \pm 1.3^{f}$ & $3.7 \pm 0.4^{b}$ \\
\hline CA2 & $64.5 \pm 0.3^{h}$ & $70.1 \pm 0.1^{f}$ & $75.8 \pm 0.4^{9}$ & $3.4 \pm 0.2^{c}$ \\
\hline CA3 & $65.4 \pm 0.1^{g}$ & $70.8 \pm 0^{\mathrm{fe}}$ & $77.5 \pm 0.1^{\mathrm{e}}$ & $5.5 \pm 0.1^{a}$ \\
\hline CA4 & $68.1 \pm 0.5^{c}$ & $74.3 \pm 0.2^{\mathrm{ba}}$ & $82.9 \pm 0.4^{a}$ & $2.3 \pm 0.2^{d}$ \\
\hline CA5 & $67.2 \pm 0.3^{\text {ed }}$ & $72.9 \pm 0.1^{\mathrm{dcb}}$ & $78.6 \pm 0.2^{d}$ & $0.9 \pm 0.1^{g f}$ \\
\hline CA6 & $69.6 \pm 0.4^{a}$ & $75.0 \pm 0.1^{a}$ & $79.7 \pm 0.5^{c}$ & $0.6 \pm 0.1^{\text {ih }}$ \\
\hline CA7 & $65.8 \pm 0.2^{g}$ & $72.1 \pm 0^{\mathrm{edc}}$ & $81.3 \pm 0.1^{b}$ & $1.7 \pm 0.2^{e}$ \\
\hline CA8 & $67.1 \pm 0.0^{\text {ed }}$ & $71.9 \pm 0.1^{\text {fedc }}$ & $78.5 \pm 0.2^{d}$ & $3.6 \pm 0.1^{\mathrm{cb}}$ \\
\hline $\mathrm{BCO} 1$ & $67.9 \pm 0.1^{c}$ & $75.0 \pm 0.1^{\mathrm{a}}$ & $82.7 \pm 0.4^{a}$ & $0.9 \pm 0.1^{g f}$ \\
\hline $\mathrm{BCO} 2$ & $68.6 \pm 0.1^{b}$ & $75.1 \pm 0^{\mathrm{a}}$ & $83.3 \pm 0.1^{\mathrm{a}}$ & $1.0 \pm 0.1^{g f}$ \\
\hline $\mathrm{BCO} 3$ & $62.9 \pm 0.0^{i}$ & $67.6 \pm 0.2^{g}$ & $74.8 \pm 0.6^{h}$ & $0.7 \pm 0.0^{\mathrm{hg}}$ \\
\hline $\mathrm{BCO} 4$ & $66.9 \pm 0.3^{e}$ & $71.9 \pm 2.1^{\text {fedc }}$ & $80.8 \pm 0.3^{b}$ & $1.0 \pm 0.1^{g f}$ \\
\hline $\mathrm{BCO} 5$ & $67.4 \pm 0.6^{d}$ & $70.3 \pm 4.2^{\mathrm{fe}}$ & $80.7 \pm 0.6^{b}$ & $0.9 \pm 0.1^{g f}$ \\
\hline $\mathrm{BCO} 6$ & $66.4 \pm 0.1^{\dagger}$ & $73.5 \pm 0.1^{\mathrm{cba}}$ & $80.9 \pm 0.1^{b}$ & $1.0 \pm 0.1^{f}$ \\
\hline BCA1 & $65.7 \pm 0.0^{g}$ & $67.9 \pm 0.0^{\mathrm{g}}$ & $73.0 \pm 0.0^{i}$ & $0.3 \pm 0.0^{i}$ \\
\hline BCA2 & $62.2 \pm 0.0^{j}$ & $71.0 \pm 0.0^{\text {fed }}$ & $78.9 \pm 0.2^{d}$ & $0.5 \pm 0.0^{\text {ih }}$ \\
\hline p-Brown-Forsythe ${ }^{\star *}$ & 0.44 & 0.12 & 0.66 & 0.23 \\
\hline p-Anova*** & $<0.0001$ & $<0.0001$ & $<0.0001$ & $<0.0001$ \\
\hline
\end{tabular}

The energy involved in starch gelatinization is represented by the $\Delta \mathrm{H}$, which is calculated from the DSC endotherms. The more cooked/toasted the flour, the more gelatinized is its starch fraction and less energy is needed for completing the process. Therefore, in the present study the $\Delta \mathrm{H}$ values represent the degree of starch gelatinization in the flours.

In the present study, the flaked flours (biju-type) had the smallest $\Delta \mathrm{H}$ values when compared with those lighter in color and with lower granulometry profile, which showed larger $\Delta H$ values. This last flours still have some amount of raw or partially gelatinized starch granules due to the processing conditions mainly during the drying/toasting step. Raw starch is one of the types of resistant starch [17].

The flaked flours had, in most cases, higher values of gelatinization temperatures $\left(T_{0}, T_{p}\right.$ and $\left.T_{c}\right)$. When starch is heated in excess water its less-stable crystallites will melt whereas the most stable crystallites that remain need more energy and higher transition temperatures are also expected [18]. Another consequence of the disruption of starch crystallites is that amorphous region will increase, facilitating water absorption for longer period, resulting in higher values for the transition temperatures $\left(T_{0}\right.$, $\mathrm{T}_{\mathrm{p}}$ and $\left.\mathrm{T}_{\mathrm{c}}\right)$. 
The BCA1 sample did not present a detectable endotherm meaning that starch seems to be completely gelatinized. Our DSC results were consistent when analyzed together with our other data, mainly the powder X-ray diffraction (Figure 3).
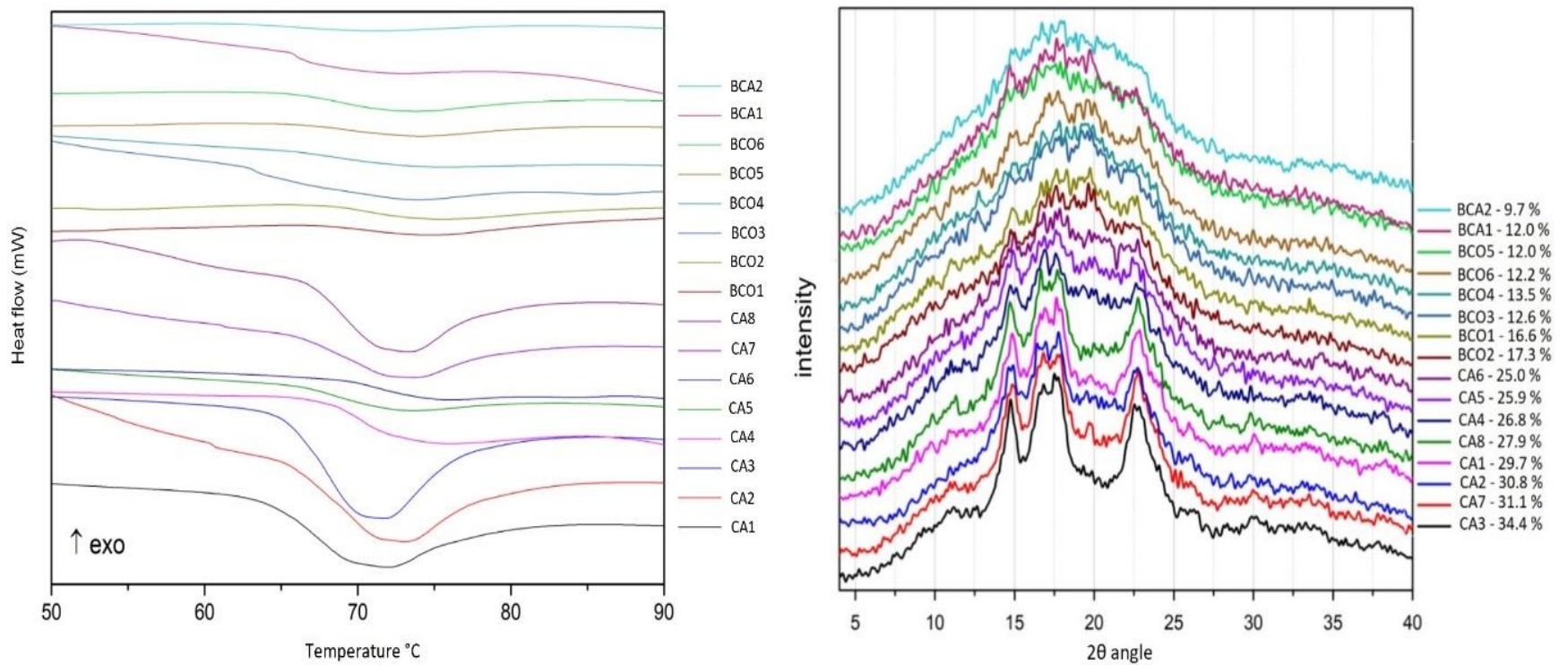

Figure 3. DSC endotherms (left) and X-ray diffractograms/relative crystallinity (right) from cassava and corn flours.

\section{Powder X-Ray diffractometry}

The relative crystallinity $(\mathrm{RC})$ calculated from the X-ray diffraction peaks of the flours differed among samples (Figure 3). Some flours presented typical diffractograms showing the native cassava starch presence, whereas others did not show any crystallinity (absence of peaks).

The cassava flours that had the highest $R C$ values showed the A-type diffraction pattern, with the most prominent peaks at $15,17,18$ and $23^{\circ}$ (20 angle), typical of cassava starch [19,20]. Flours CA3, CA2, CA7, CA1 and CA8 had the sharpest peaks, i.e., the highest RC values, ranging from $34.4 \%$ to $27.9 \%$. These values are in line with those reported for cassava raw starch [20].

The cassava flours CA4 and CA5 had less visible peaks and RC values $26.8 \%$ and $25.9 \%$, respectively. The flaked cassava flours (BCA1 and BCA2) showed very small peaks meaning that almost no raw starch remained due to the high degree of gelatinization (DG); the RC values of those flours were $12.0 \%$ and $9.7 \%$, respectively. When comparing our results with a study that dried cassava starch by spray-drying and by extrusion [20], a similar behavior of the RC values is observed: $35.6 \%, 26.5 \%$ and $0 \%$, for the native (raw), spray-dried and extruded cassava starch, respectively.

All corn flours from our study were flaked (biju-type), therefore have passed through cooking conditions that favored complete gelatinization of the starch. These results are in line with previous reported ones for cooking tests of corn starch at different temperatures [21]. The typical peaks at $15,17,18$ and $23^{\circ}(2 \theta$ angle) of corn starch (A-type) were not present due to starch gelatinization. There was a tiny peak at $20^{\circ}$ ( $2 \theta$ angle) in the sample $\mathrm{BCO} 2$, which can be attributed to the amylose-lipid complex. This was the corn flour with the highest lipid content $(4.1 \%)$ followed by the sample BCO1 $(2.7 \%)$, whereas the other corn flours had low lipid levels $(0.17 \%$ to $1.15 \%)$. The amylose-lipid complex hinders starch digestion, being termed as resistant starch type "V". 


\section{Scanning Electron Microscopy (SEM)}

The cassava starch showed predominantly round-shaped granules concave-convex with few depressions (Figure 4). The cassava flour CA3 has raw and partially gelatinized starch granules, which are evidenced by the shrunken aspect of some granules that have swollen during cooking and then shrivelled during cooling. This behavior was also reported in another study that spray-dried cassava starch [22]. Following a similar trend, the flours CA1, CA2 and CA8 also had raw and gelatinized granules. These samples had considerable amounts of RS.

One of the cassava flours (CA6) with small granulometry had a distinct behavior when compared with the others. The referred sample had some gelatinized fractions blended with raw starch. Its RS content was lower than those of other samples, but it had higher SDS level.

Contrasting with the other cassava flours, the sample BCA1 had only a homogeneous appearance as if a gel has been formed and dehydrated with complete disintegration of the starch granular structure. This sample had the highest RDS value and absence of RS.

In general, the dry cassava flours (CA1 -CA8) presented starch granules with more intact structures when compared with those from the flaked flours (BCO1 - BCO6, and BCA1 - BCA2), which showed melted structures due to the gelatinization. Differences in the processes of production of the flours are responsible for the DG of starch. These differences involve moisture contents of the grated cassava pulp and of the grinded corn endosperm as well as the temperature of the drying surface of the oven and the time of contact with the hot plate necessary to produce the desired color of the flours.

Cassava flour is produced from grated and pressed (manual or hydraulic pressing) cassava pulp, whilst corn flour production involves corn kernel or corn endosperm steeping in pot water for 24-48 $\mathrm{h}$ followed by grinding and sieving. After that, the moist material is poured onto a hot plate oven and due to the relative high moisture level starch gelatinizes and flaking takes place. 

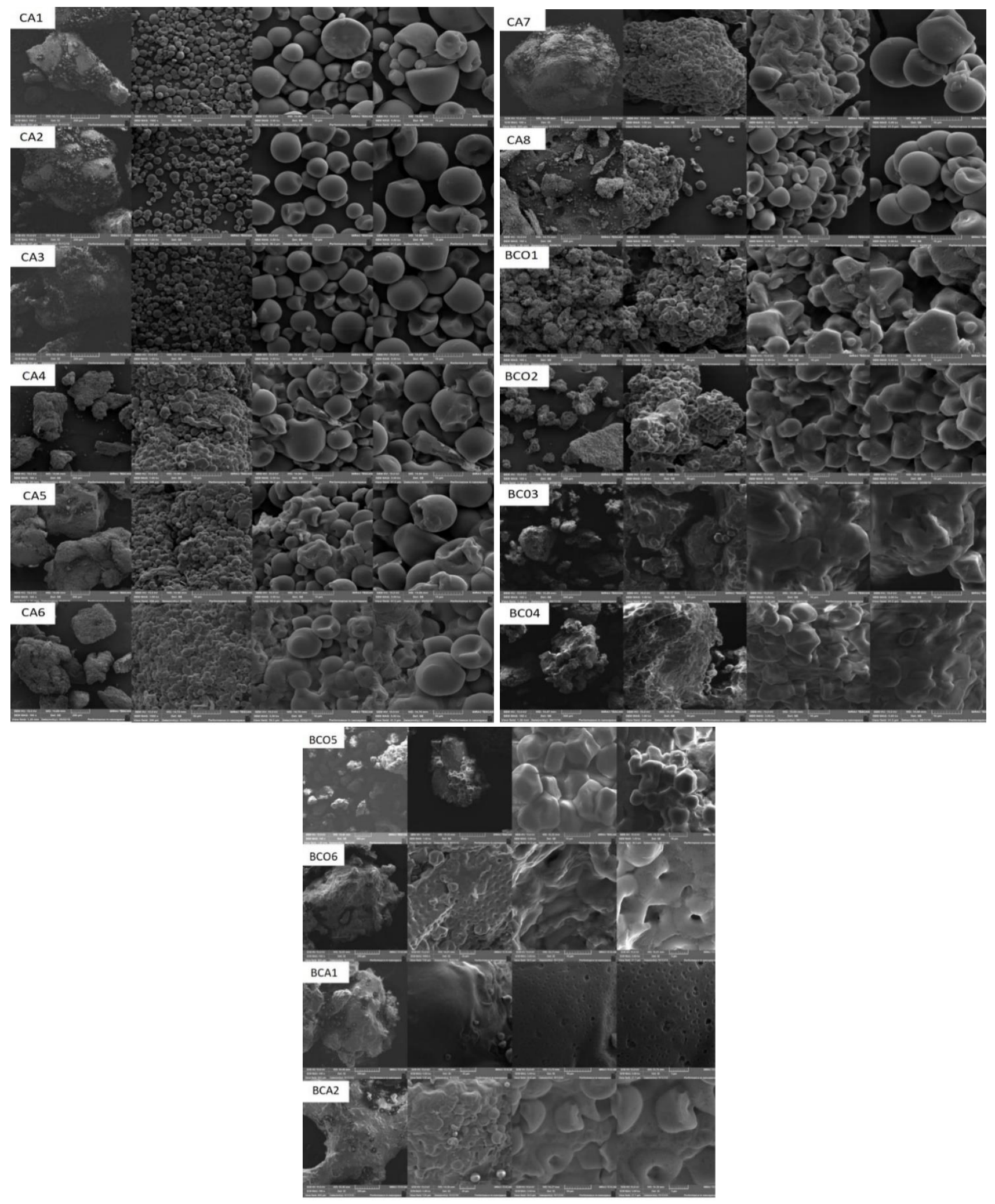

Figure 4. SEM micro images of the flours (dry cassava - CA1-CA8, flaked cassava - BCA1 - BCA6 and flaked corn BCO1 - BCO2); from left to right: magnifications of $0.1,1.0,3.5$ and $5.0 \mathrm{kx}$

\section{In vitro starch digestibility}

The results of the in vitro starch digestibility from the flours show the values of RDS, SDS and RS (Figure 5). 


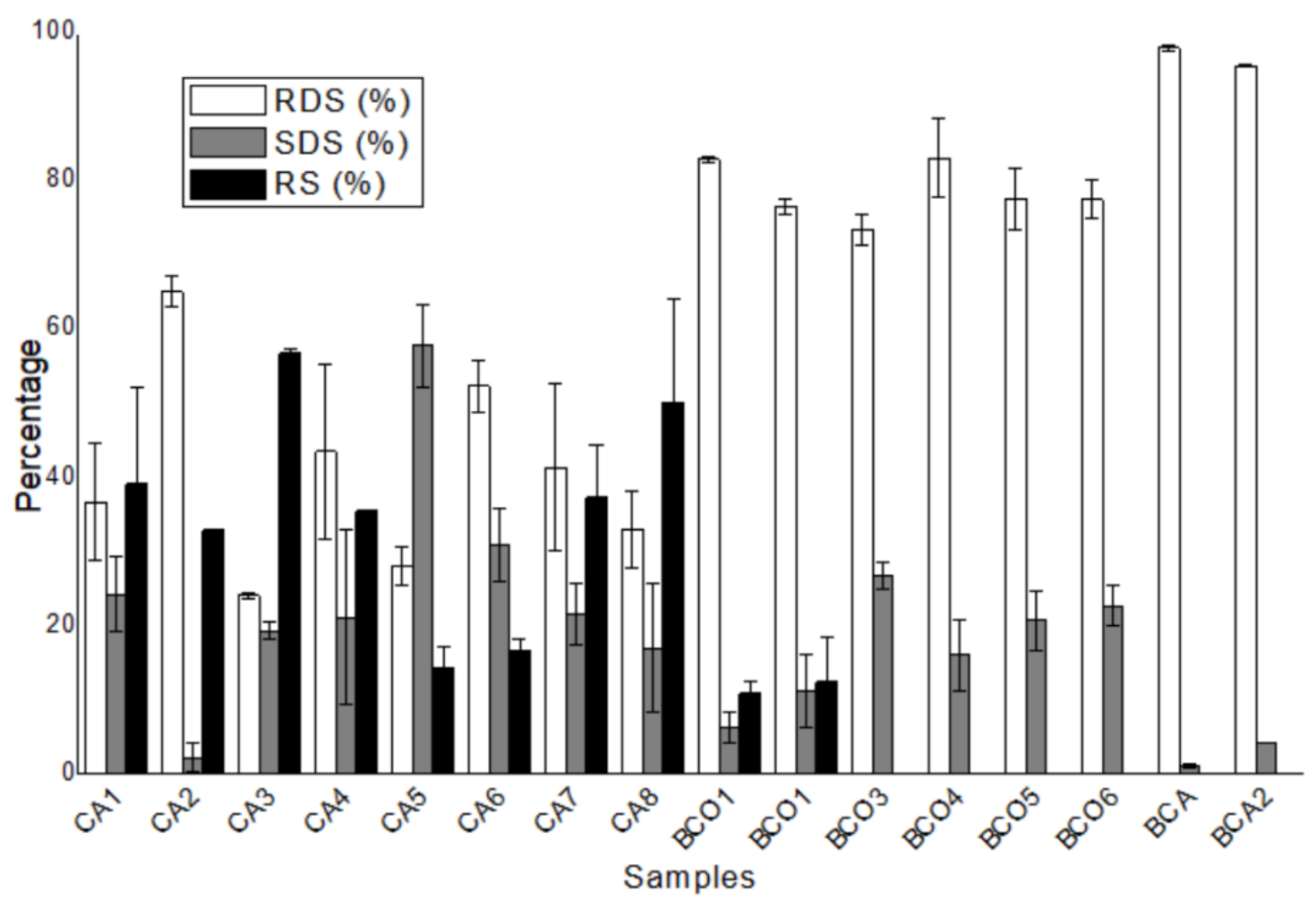

Figure 5. In vitro starch digestibility of the cassava and corn flours.

RDS values and the percentage of coarser particles of the flours $(>1.190 \mathrm{~mm})$ were correlated $(r=$ $0.80, \mathrm{p}<0.05$ ). This material with the larger granulometry was present only in the flaked flours (biju-type), i.e., BCO1-BCO6 and BCA1-BCA2 that were the samples that had the highest RDS values.

The smaller the granulometry of a substrate, like flour, the higher the surface/volume ratio, therefore favorable conditions for higher enzymatic hydrolysis rates would be expected $[23,24]$. Our results, however, showed a distinguished behavior.

If we have analyzed the same flours with different degrees of grinding and sieving, the expected values should be found. In our study, however, we were interested in testing the flours "as were" for marketing/consumption to understand the effect of the different processing conditions.

The flaked flours, with bigger particles, also had the lowest values for $R C, \Delta H$ and RVA-viscosity peak. Pearson correlation coefficients between these variables and RS were significant $(r=0.93,0.90$ and 0.64 , between RS and RC, RS and $\Delta \mathrm{H}$, and RS and RVA-viscosity peak, respectively). Starch digestibility is deeply influenced by the starch structure, with a central role of the double helices of the crystalline domains of the raw, uncooked granules. When starch is cooked with excess water, gelatinization is promoted with uncoiling and opening of the tight ordered structure of the granules facilitating the action of amylases [25].

Other of our results (XRD, DSC and RVA) also have showed that the RS values were higher in the samples containing granular starch, visible in the SEM images, whereas those samples with melted starch structures presented the lower RS values. Consequently, the flours with higher DG (observed by DSC, SEM, XRD) had the highest percentages of RDS. This was the case of the two samples of flaked cassava flours (BCA1 and BCA2), which showed completely melted aspect under SEM. The samples with intermediary behavior presented the highest percentages of SDS.

Interestingly, the flours with very fine granulometric fractions $(<0.250 \mathrm{~mm})$ had the highest contents of granular starch and the percentage of particles correlated positively with the RS levels $(r=0.87, p<0.05)$.

Rapid digestion in the present study was associated with flours that had the lower $\mathrm{RC}$ values associated with flat $\mathrm{X}$-ray diffractograms and the lowest values of $\Delta \mathrm{H}$; these flours also presented high WHC and their starch granules were partially melted forming agglomerated structures (SEM images). These results are in line with the literature [20,22,25].

Our study showed that the flaked flours had high digestibility (>RDS) whereas the dry cassava flours had a slower digestion process. The production of those two types of flour differs, and for the flaked flour, the moisture values of the grinded raw materials (cassava or corn) are higher and the drying/toasting temperatures are also higher if compared with the dry flours. 
Considering the results for instrumental color ( $b^{*}$ value), no direct relation was found with the levels of RDS. The two dry cassava flours with the lowest RS contents (CA6 and CA5) were placed in the second and third positions in terms of $b^{*}$ values. The yellower color of those samples is probably due to the more severe toasting that gelatinizes and may promote partial starch dextrinization resulting in lower RS contents [26].

One exception was the sample CA4, which had the highest $b^{*}$ value but did not follow the abovedescribed trend. In this case, a high RS value was associated with the yellow color $\left(b^{*}\right)$. This can be explained by the color of the raw material pulp as well as some difference in the processing that could result in coarser and denser particles that did not dissolve easily during the analysis procedures adopted in this study. Considering that CA4 had the highest dietary fiber content $(5.6 \%)$ from all flours, some contamination with cassava root external peel could have also happened during its processing.

A slower digestibility trend was detected for the flours that presented the highest moisture levels suggesting again the effect of drying conditions in this relevant nutritional parameter. As mentioned above, peeled cassava roots are grated, pressed and dried/toasted; the bigger the granulometry after grating, the most difficult, time-demanding is the drying step and possibly more water remains in the material that cooks on the oven hot surface with starch gelatinization. The Brazilian cassava flour is processed in a particular way, resembling the African Gari processing [27], except for the fermentation step that is absent for the type of flours from the present study (from Southern region of Brazil). This cassava flour processing differs from another process previously described elsewhere [28].

Excessive water removal during the pressing step generates more liquid residues (effluent) as well as reduction of the final yield; if the pressing step is controlled less water will be removed and the final moisture of the toasted flours can be higher. Also, the presence of higher moisture levels when the grated cassava pulp arrives to the oven favors starch gelatinization [29].

Therefore, darker cassava flours with higher moisture contents, generally have a faster starch digestion than lighter color ones that also have lower moisture values due to the moisture level when the material was taken to the oven and also the oven temperatures.

The sample CA5 was very similar to another one (CA6) when considering their dietary fiber content, $\mathrm{RC}$ and chemical composition. CA5, however, had the highest SDS from all samples, differently from CA6. The only distinction between them was the RVA-viscosity that was pretty higher for CA5; more viscous media will difficult $\alpha$-amylase mobility and will slow digestion [30]. There was also a difference between the granulometry profile of those two samples, CA6 coarser and CA5 finer.

Briefly, the flours that had more gelatinized starch and smaller granulometry gave higher SDS percentages, which is could be related with their higher viscosity. When comparing those samples with a flour in which starch gelatinization was not so severe, they will have lower RS content.

The CA2 had one of the smallest SDS contents and an intermediary value for RS. A possible explanation is that part of the flour would be gelatinized but some starch granules would not. This particular flour presented small particle size and we were expecting that it would present a low RDS percentage, but this was not the case; this shows that both microscopic and macroscopic properties must be taken into consideration when analyzing starch digestibility in this type of flour.

When considering the corn flours from the present study, they were all flaked (biju-type) and the results divided them into two groups: those with some amount of RS (BCO1 and BCO2) and the others, without any RS. SEM images (up to 5000x magnification) show raw starch granules. Those two samples were the only ones with higher moisture levels among the studied corn flours, suggesting that the drying step was shorter/milder favoring the maintenance of some amount of uncooked starch granules and consequently some amount of RS was found. Besides that, the RC values were higher confirming their lower DG of starch.

The sample BCO2 had the highest contents of ash and lipids, indicative of the presence of germ and pericarp. This could increase the presence of inaccessible starch occluded in the cell walls of the corn kernel as well as amylose-lipid complex that would also difficult the enzymatic digestion. Taking a look at the XRD analysis (BCO2), there was a slight peak at $20.0(2 \theta)$, which is associated with the amylose-lipid complex (RS-V).

Four groups of flours were found when looking at the results. The first group includes the flours with high DG, as confirmed by SEM images and that have the highest values for RDS. The second group of flours had partial starch gelatinization with blend of gelatinized and raw granules (SEM images at 3500x), producing inaccessible areas that limited digestion to some extent (CA3 and CA1). Those flours had a slower digestion and higher RS contents. The third group comprises intermediary DG, in which the starch 
granules would not be inaccessible but adhered to the surface of melted fractions, in samples with high RS and low SDS levels (CA2). The fourth group are flours with a combination of the granulometry and DG that favored the content of SDS.

The percentages of RS showed a strong relation with the amounts of raw starch present in the samples. Our results showed a large quality variability of the flours available in the market of Southern Brazil. In other Brazilian regions this quality heterogeneity was also reported [15,31].

Few studies are available to show the quality variability of ready-to-eat flours from South Brazil as well as how cassava and corn flours are different. Great variability in terms of structural, physicochemical and digestion properties was showed by the present study.

\section{CONCLUSION}

This study of ready-to-eat cassava and corn flours showed that SEM images give relevant information upon starch digestibility.

Aside from granulometry, dietary fiber contents and type of raw material, the producing processes deeply interfere on the nutritional quality of ready-to-eat flours resulting in higher or lower degree of starch gelatinization that exerts great influence in the starch digestibility.

The cassava flours with light color presented slower starch digestibility when compared with those darker in color and also had higher moisture levels due to lower drying temperatures or milder conditions of drying (time and temperature, moisture at the beginning of drying step).

The consumption of cassava flour as side dish, i.e., without further cooking in water, mainly those types described in the present study as containing higher levels of SDS and RS can represent a complimentary source of those beneficial starch fractions that together with other healthy life habits can represent an additional help to improving the consumer's quality of life.

Funding: This research benefited from financial support and scholarships from CAPES (DS/PROAP/PróEquipamentos), CNPq (304260/2019-3) and FINEP (Brazil). LGL, AN and IMD are research fellows from CNPq.

Acknowledgments: The authors are also grateful to the C-LABMU/PROPESP/UEPG for the support with laboratory facilities.

Conflicts of Interest: The authors declare no conflict of interest. The funders had no role in the design of the study; in the collection, analyses, or interpretation of data; in the writing of the manuscript, or in the decision to publish the results.

\section{REFERENCES}

1. Capobiango M, Vieira CR, Silva ALS e, Coelho JV, Segall SD, Silvestre MPC. Chemical and enzymatic extractions of proteins from Brazilian corn flour. Food Sci Technol. 2006;26:884-90.

2. Filho IK, Jaski AC, Takayanagui MM, De Andradre CK, Butik M, Quinaia SP. Determination and chemometric evaluation of the mineral profile of maize flours. J Food Compos Anal [Internet]. 2020;92. Available from: https://www.scopus.com/inward/record.uri?eid=2-s2.0-

85087501163\&doi=10.1016\%2Fj.jfca.2020.103579\&partnerID=40\&md5=b25fbb1a3571a8f902dab3059f56241a

3. AOAC. Association of Official Analytical Chemists. In: Official Methods of Analysis. 17a. Gaithersburg:AOAC; 2000.

4. IAL. Métodos químicos e físicos para análise de alimentos [Chemical and physical methods for food analysis]. In: Normas Analíticas do Instituto Adolfo Lutz. 3rd ed. São Paulo: IMESP; 2008. p. 42-3.

5. AOAC. Association of Official Analytical Chemists. In: Official Methods of Analysis. 16a. Arlington: AOAC; 1995.

6. Falade KO, Onyeoziri NF. Effects of Cultivar and Drying Method on Color, Pasting and Sensory Attributes of Instant Yam (Dioscorea rotundata) Flours. Food Bioprocess Technol. 2012;5(3):879-87.

7. Hsu C-L, Chen W, Weng Y-M, Tseng C-Y. Chemical composition, physical properties, and antioxidant activities of yam flours as affected by different drying methods. Food Chem. 2003;83(1):85-92.

8. Demiate IM, Wosiacki G, Cereda MP, Mestres C. Características viscoamilográficas de amidos de mandioca quimicamente modificados [Viscoamylography of chemically modified cassava starches]. Publ UEPG Ciências Exatas e da Terra, Ciências Agrárias e Eng. 2005;11(1):7-17.

9. Wang SH, Fernandes SM, Cabral LC, Araujo FB. Absorção de gordura, solubilidade e propriedades espumantes dos extratos hidrossolúveis desidratados de arroz e soja [Absorption of oil, solubility and foaming properties of dehydrated hydro soluble extracts form rice and soybean]. Ciência e Tecnol Aliment. 2000 Aug;20(2):187-91.

10. Beninca C, Demiate IM, Lacerda LG, Carvalho Filho MAS, Ionashiro M, Schnitzler E. Thermal behavior of corn starch granules modified by acid treatment at 30 and $50^{\circ} \mathrm{C}$. Eclet Quim. 2008;33(3). 
11. Nara S, Komiya T. Studies on the relationship between water-saturated state and crystallinity by the diffraction method for moistened potato starch. Starch. 1983;35(12):407-10.

12. Ratnayake WS, Jackson DS. A new insight into the gelatinization process of native starches. Carbohydr Polym. 2007;67(4):511-29.

13. Englyst ON, Hudson GJ, Englyst HN. Starch analysis in food. In: R. A. Meyers, editor. Encyclopedia of analytical chemistry. 1st ed. Chichester: John Wiley \& Sons; 2000. p. 4246-4262.

14. Pereira BLB, Leonel M. Resistant starch in cassava products. Food Sci Technol. 2014;34(June):298-302.

15. Dias LT, Leonel M. Caracterização físico-química de farinhas de mandioca de diferentes localidades do Brasil [Physicochemical characterization of cassava flours from different regions from Brazil]. Cienc. e Agrotecnologia. 2006;30:692-700.

16. Iftikhar SA, Dutta H. Status of polymorphism, physicochemical properties and in vitro digestibility of dual retrogradation-annealing modified rice starches. Int J Biol Macromol. 2019;132:330-9.

17. Englyst $\mathrm{HN}$, Kingman $\mathrm{SM}$, Cummings $\mathrm{JH}$. Classification and measurement of nutritionally important starch fractions. Eur J Clin Nutr. 1992;46:33-50.

18. Wang S, Xiu Z, Shuo W, Les $\mathrm{C}$. Changes of multi-scale structure during mimicked DSC heating reveal the nature of starch gelatinization. Sci Rep. 2016;6.

19. Zhu F. Composition, structure, physicochemical properties, and modifications of cassava starch. Carbohydr Polym. 2014;122:456-80.

20. Santos TPR, Franco CML, Demiate IM, Li XH, Garcia EL, Jane J lin, et al. Spray-drying and extrusion processes: Effects on morphology and physicochemical characteristics of starches isolated from Peruvian carrot and cassava. Int J Biol Macromol. 2018;118:1346-53.

21. Fu Z-Q, Wang L-J, Li D, Adhikari B. Effects of partial gelatinization on structure and thermal properties of corn starch after spray drying. Carbohydr Polym. 2012;88:1319-25.

22. Santos TPR, Franco CML, do Carmo EL, Jane J, Leonel M. Effect of spray-drying and extrusion on physicochemical characteristics of sweet potato starch. J Food Sci Technol. 2018;

23. Farooq AM, Li C, Chen S, Fu X, Zhang B, Huang Q. Particle size affects structural and in vitro digestion properties of cooked rice flours. Int J Biol Macromol. 2018 Oct;118:160-7.

24. Kendall CW, Esfahani A, Jenkins DJ. The link between dietary fibre and human health. Food Hydrocoll. 2010;24:42-8.

25. Liu X, Mu T, Sun H, Zhang M, Chen J, Fauconnier ML. Influence of different hydrocolloids on dough thermomechanical properties and in vitro starch digestibility of gluten-free steamed bread based on potato flour. Food Chem. 2018;239(June 2003):1064-74.

26. Martínez MM, Román L, Gómez M. Implications of hydration depletion in the in vitro starch digestibility of white bread crumb and crust. Food Chem. 2018;239:295-303.

27. Oyeyinka SA, Ajayi OI, Gbadebo CT, Kayode RMO, Karim OR, Adeloye AA. Physicochemical properties of gari prepared from frozen cassava roots. LWT. 2019 Jan;99:594-9.

28. Aristizábal J, García JA, Ospina B. Harina de yuca refinada en panificación: Una revisión [Refined cassava flour in breadmaking: a review]. Ing e Investig. 2017;37(1):25-33.

29. Guo P, Yu J, Wang S, Wang S, Copeland L. Effects of particle size and water content during cooking on the physicochemical properties and in vitro starch digestibility of milled durum wheat grains. Food Hydrocoll. 2018;77(29):445-53.

30. Ma Y-S, Pan Y, Xie Q-T, Li X-M, Zhang B, Chen H-Q. Evaluation studies on effects of pectin with different concentrations on the pasting, rheological and digestibility properties of corn starch. Food Chem. 2019;274:31923.

31. Souza JML De, Negreiros JRDS, Álvares VDS, Leite FMN, Souza ML De, Reis FS, et al. Variabilidade físicoquímica da farinha de mandioca [Physicochemical variability of cassava flour]. Ciência e Tecnol Aliment. 2008;28(4):907-12.

(C) (5) 2021 by the authors. Submitted for possible open access publication under the terms and
conditions of the Creative Commons Attribution (CC BY NC) license
(https://creativecommons.org/licenses/by-nc/4.0/).

